\title{
Predictors of Prenatal Breastfeeding Self-Efficacy in Malaysian Women: A Cross-Sectional Study
}

\author{
Syahrul Bariah Abdul Hamid ${ }^{1 *}$, Nurshazlyana Mohamad Zaidi ${ }^{1}$
}

Mother, Infant \& Young Child Nutrition (MiChild) Research Group

Centre of Nutrition of Dietetics, Faculty of Health Science, Universiti Teknologi MARA (UiTM)

Cawangan Selangor, Kampus Puncak Alam, Selangor, 42300 Puncak Alam, Selangor, Malaysia

\begin{abstract}
Mothers with better self-efficacy are tend to have intent to breastfeed, initiate early and have lengthier of exclusive breastfeeding. This study aimed to evaluate the level of breastfeeding selfefficacy and to investigate the determinants of breastfeeding self-efficacy among pregnant mothers. A total of 180 expecting mothers were recruited in this cross sectional study from chosen Maternal and Child Health Clinics in Selangor. Self-administered questionnaires of Iowa Infant Feeding Attitude Score (IIFAS) and Breastfeeding Self-Efficacy (BSES-SF) were used to attain information on maternal attitudes and knowledge of breastfeeding and breastfeeding self-efficacy. Findings showed subjects had high level of breastfeeding self-efficacy (mean $51.79 \pm 11.94$ ) and majority of them had fair knowledge in breastfeeding. Breastfeeding self-efficacy is found associated with number of children, while, residential area, occupation and household income were associated with breastfeeding knowledge $(\mathrm{p}<0.05)$. The best-fit regression analysis revealed three variables that explained $41.0 \%$ of the variance in breast feeding self-efficacy among expectant mothers. They were being housewife, multiparous and had positive breastfeeding attitudes $(p<0.05)$. For that reason, healthcare providers can tactically identify women vulnerable to low breastfeeding self-efficacy by providing early intervention through increasing the awareness and knowledge in breastfeeding during prenatal and antenatal.
\end{abstract}

Keywords: breastfeeding knowledge, breastfeeding self-efficacy, theory planned behaviour

\section{INTRODUCTION}

Breastfeeding can improve development, well-being and survival of children. Breast milk not only defenses the well-being during childhood, but also offers long term protection throughout life (Binns et al. 2016). There is a vast evidence on both long and short term benefits of breastfeeding for mothers and children and its positive effects on supporting mental, physiological health and development through nutrition in breast milk in reducing morbidity and mortality rates in children especially during the first few months of life (Victora et al. 2016; Eidelman et al. 2012).

In Malaysia, despite numerous supports and campaigns piloted by the government, the breastfeeding rates are still lower than the rate recommended by WHO (2019). Despite the fact that the breastfeeding rates have increased since year 2006, according to the
National Health and Morbidity Survey, only $47.1 \%$ and $98.1 \%$ of infants under 6 months were exclusively breastfed and ever breastfed respectively (Institute for Public Health 2016). In addition, prevalence of timely initiation was $65.3 \%$ and the continued prevalence of breastfeeding up to two years was only $39.4 \%$. However, the rates were far below than the recommended by WHO regardless of numbers of awareness programs on benefits of breastfeeding extensively moderated by the government.

Present study also has observed the relationship between many variables and their impact on breastfeeding outcomes; timely initiation, duration of breastfeeding and exclusivity of breastfeeding (Castro et al. 2017). Key factors such as maternal attitudes, breastfeeding self-confidence and breastfeeding self-efficacy demonstrate a positive relationship with sustained

"Corresponding Author: tel: +60332584382, email: syahrulbariah@warga.uitm.edu.my 
breastfeeding and some evidence exists that these variables may be modifiable towards experiences in breastfeeding (Leahy-Warren et al. 2014; Meedya et al. 2010).

Breastfeeding self-efficacy denotes to a mother's ability or confidence to breastfeed her newborn as she perceived and this inflict her choices on early initiation of breastfeeding, exclusivity and duration of breastfeeding as well as how she will tackle any breastfeeding issues (Dennis 1999). To increase breastfeeding self-efficacy, a mother must have the beliefs that breastfeeding will produce positive outcomes and also mothers must display the confidence in executing the specific behaviour which is breastfeeding. Past exposure to breastfeeding experiences plays an important roles to explain attitude, subjective norms and self-efficacy of mothers to their next breastfeeding practice as intention to breastfeed were predicted by subjective norms and attitude mothers to the formula-feeding and also mothers breastfeeding experience (Bartle \& Harvey 2017).

Higher perceived breasfeeding selfefficacy mothers tend to initiate breastfeeding early and continue to breastfeed despite facing challenges during breastfeeding, meanwhile, mothers with a lower perceived self-efficacy may do not have the intention, delay the initiation or wean in advance due to lack of confidence or ineffective coping skills. Therefore, mothers with have higher self-efficacy or breastfeeding control are tend to have positive breastfeeding outcomes (Zhu et al. 2016).

According to Dennis (1999), who developed Theory of Breastfeeding SelfEfficacy, the choice to breastfeed is influenced by four processes which are; if the mother decides to breastfeed or not, how much effort that the mother needs, is the mother has a selfencouraging pattern of thinking and how the mother tackles the problem of breastfeeding difficulties (Dennis 1999). Bandura (1977) suggested that social supports, personal experience, vicarious involvement, verbal encouragement and emotional and physiological condition may influence a mother's efficacy to breastfeed. Higher perceived social support mothers were associated with higher level of breastfeeding self-efficacy and linked to increased intention to breastfeed, early initiation of breastfeeding and longer duration of breastfeeding (Mannion et al. 2013; Yang et al. 2016; Mirghafourvand et al. 2018).

Therefore, breastfeeding self-efficacy during pregnancy could be a predictor of positive breastfeeding outcomes. It also can be an indicator to identify those who need further assistance to warrant continuance of breastfeeding. However, no study has been carried out to measure breastfeeding selfefficacy level and investigate the predictors of breastfeeding self-efficacy among Malaysian expectant mothers.

\section{METHODS}

\section{Design, location \& time}

This cross sectional study was conducted among expecting mothers who attending chosen Maternal and Child Health Clinics in Selangor, Malaysia.

Convenience sampling was used in this study with inclusion criteria as follows; eligible pregnant mothers and willing to participate in the study, singleton pregnancy, age between 18-41 years old, could speak and read in English or Malay. They will be excluded from participation if they had serious medical or obstetric conditions and multiple pregnancies (twins, triplets).

This study was conducted in Selangor from September to November 2017. Selangor is one of the most populous state located in Peninsular Malaysia. Two Maternal and Child Health clinics in Kuala Selangor district were chosen for this study.

\section{Sampling}

The sample size was calculated based on any given population using Krejcie and Morgan (1970) table in determining sample size. Given the nearest population size of 360 , the determined sample size was 180 subjects. Thus, for the purpose of this study, 180 pregnant mothers were recruited during their antenatal examinations.

\section{Data collection}

The data collection was in the form of self-administered questionnaire. Data included were socio-demographic, maternal attitudes towards infant feeding and breastfeeding selfefficacy. 
This study used a validated Breastfeeding Self Efficacy Scale-Short Form (BSES-SF) that was translated into Malay language instrument to evaluate level of breastfeeding self-efficacy among expectant mothers. The Cronbach's Alpha value for Malay version of antenatal BSES-SF questionnaire was 0.94 (Husin et al. 2017). This Breastfeeding Self Efficacy Scale-Short Form (BSES-SF) was originally has 33 questions and has been simplified into 14 questions (Dennis 2003). In this instrument, all questions are begin with phrase "I can always". The score uses the Likert scale which start from 1 for not confident at all to 5 for very confident. Higher marks directed higher levels of breastfeeding self-efficacy. Furthermore, outcome expectancy and self-efficacy expectancy are two components in self-efficacy concept. In order to predict how long mothers will continue to breastfeed, Breastfeeding selfefficacy Scale (BSES) is the best predictor that can be used. In BSES-SF, the minimum and maximum scores were 14 and 70 respectively. The scores of less than 50 indicates higher risk for breastfeeding cessation. The information used in BSES-SF is about the confidence in producing adequate breast milk, exclusive breastfeeding, using formula milk, correct latching, breastfeeding in public and satiety of the baby.

The Iowa Infants Feeding Attitude Scale (IIFAS) consists of 17 questions to measure the level of attitude in breastfeeding. The questions were divided into positive to breastfeeding and positive to artificial feeding. Scoring for questionnaires is based on a Likert scale from 1 to $5 \quad(1=$ absolutely disagree, $2=$ disagree, $3=$ no idea, $4=$ agree, and $5=$ absolutely agree). The IIFAS has been translated and validated in Malay language and have been used among mothers in Malaysia (Shukri et al. 2017). The Cronbach's alpha for this instrument was 0.7-0.8 (Karande \& Parkar 2012). Greater scores directed to a more positive attitude to breastfeeding. Questions of 1, 2, 4, 6, 8, 10, and 13 were scored reversely. This questionnaire is reliable and valid, the Cronbach's alpha was stated between 0.85-0.86 (Mora et al. 1999). The total attitude scores range from 17 (indicating positive attitudes towards artificial feeding) to 85 (reflecting positive attitudes towards breastfeeding) while the score of 51 indicated a neutral attitude.
Permissions were attained from the subjects by written informed consent. The subjects were informed that the participation was voluntarily and their administered data would be assured confidentially for the purpose of the study only. This study was approved by UiTM Research Ethics Committee (REC/151/17) and Medical Research Ethics Committee, Ministry of Health (NMRR-171299-36056).

\section{Data analysis}

Data is analyzed using the Statistical Package for Social Sciences (SPSS) version 21.0 software. Descriptive statistics were calculated for socio-demographic data such as age, ethnicity and household income. Normality test was carried out using Kolmogorov-Smirnov Test of Normality. Differences of breastfeeding self-efficacy among mothers from different sociodemographic characteristics were analysed by one-sided independent sample t-test or one way ANOVA. Significant variables $(p<0.05)$ were included in the multiple linear regressions to investigate the predictors of the breastfeeding self-efficacy.

\section{RESULTS AND DISCUSSION}

\section{Sample characteristics}

Table 1 showed a total 180 pregnant women took part in this study. The age of participants diversed from 19 and 41 years old. More than half of the expectant mothers $(69.4 \%)$ were aged between 19 to 30 years old. Most participants were Malay (91.7\%) and only $(8.3 \%)$ are non-Malay. More than half $(62.8 \%)$ of our participants were working mothers. A total of $65.6 \%$ of respondents received education up to (more than 12 years of education) and $58.3 \%$ of the mothers had children more than one. The majority $(81.1 \%)$ of the mothers were neutral and only $16.7 \%$ of the mothers had positive attitude towards breastfeeding.

In addition, this study reported that majority mothers who had high knowledge, imposed more positive attitude towards breastfeeding with mean score of 63.32 \pm 5.96 . The finding is supported by a randomized controlled study done to evaluate the 
effectiveness of prenatal breastfeeding workshop. It is suggested mothers with higher knowledge on breastfeeding practices and benefits of breast milk had higher possibilities to have higher score of breastfeeding selfefficacy and resulted to longer duration of exclusive breastfeeding (Noel-Weiss et al. 2006). Similar finding from Bartle and Harvey also found higher maternal breastfeeding selfefficacy during pregnancy is associated with higher intention to breastfeed and therefore, predicted better breastfeeding outcomes (Bartle \& Harvey 2017).

There was a significant statistical association between breastfeeding selfefficacy and parity in this study as seen in Table 1. This finding aligned with study done by Draman and friends in 2017, they found that previous breastfeeding practice had a significant association with current exclusive breastfeeding practices. However, results of a study by Bartle and Harvey (2017) on mothers who were multiparous showed that past experience of birth and breastfeeding practices predicted attitudes and subjective norms that were in favor of breastfeeding but not to their breastfeeding self-efficacy. While in the other hand, having experienced difficulties in breastfeeding imposed lower breastfeeding self-efficacy.

\section{Breastfeeding self-efficacy}

The objective of this present study was to assess the level of breastfeeding selfefficacy and investigate its determinants among pregnant mothers. Table 2 showed mean, median and standard deviation values for each question on the BSES-SF. The present study found that the mean score of breastfeeding self-efficacy among expectant mothers was $51.79(\mathrm{SD}=11.94)$. A similar pattern of mean scores were observed in two psychometric analysis studies which were $56.20(\mathrm{SD}=8.75)$ and 58.52, respectively (Husin et al. 2017; Alus-Tokat et al. 2010). These mothers had high self-efficacy towards breastfeeding and it is suggested could be due to more than $50 \%$ of the expecting mothers had more than one child and they may have past exposure in breastfeeding as discussed in several other studies (Mirghafourvand et al. 2018; Husin et al. 2017).
The three items that had the uppermost scores were 'confidence to be able to breastfeed exclusively', 'coping with breastfeeding' and 'personal desire to breastfeed'. The items that had the bottommost score were 'continue to breastfeed at every feed' and 'finishing feeding my baby before switching to the other breast', suggesting mothers had lowest confidence in these perspectives.

Further investigation on the breastfeeding self-efficacy items in the present study proposed that mothers had minimal confidence on appropriate timing to finish feeding and either their milk supply is adequate to sustain with the baby's demand. The findings were similar to Finnish and Chinese studies which highlighted the mothers' concern on milk insufficiency to achieve the baby's demand and breastfeeding without supplementing with formula milk (Yang et al. 2016; Koskinen et al. 2014).

\section{Predictors of breastfeeding self-efficacy}

Table 3 shows the variables that have significant relationship with BSES-SF scores which were counted in the stepwise regression model. The best-fit regression model discovered that there are three variables that explained $41.0 \%$ of the variance in BSES-SF scores. The final determinants for breastfeeding self-efficacy among expectant mothers were having more than one child, being housewife and positive attitude towards breastfeeding. Therefore, the predicted of expected breastfeeding self-efficacy is written in this equation: $\mathrm{Y}(\mathrm{BSES})=21.00+(0.579 \mathrm{x}$ positive towards breastfeeding $)+(4.826 \mathrm{x}$ housewife $)$ $+(4.208 \times$ multiparous $)$. From this equation, each one score increase in breastfeeding selfefficacy is associated with a 0.579 increase with positive attitude towards breastfeeding, a 4.826 increase with being housewife and 4.208 increase in mothers with multiparous. These variable statistically significant in predicting breastfeeding self-efficacy, F (8.171) $=4.323$, $\mathrm{p}<0.05, \mathrm{R} 2=0.410$.

In the present study, it is understood that parity was a predictor of breastfeeding self-efficacy. In Table 1 depicted multiparous mothers $(54.05 \pm 10.82)$ hadhigherbreastfeeding self-efficacy compared to uniparous mothers (48.60土12.76). This is also supported by a 
Table 1. Characteristics of respondents $(n=180)$

\begin{tabular}{|c|c|c|c|c|}
\hline Socio-demographic factors & $\mathrm{n}$ & Percentage (\%) & Mean (SD) & $\mathrm{p}$ value \\
\hline Age (years) & & & & 0.292 \\
\hline $19-31$ & 125 & 69.4 & $51.16(12.18)$ & \\
\hline $31-41$ & 55 & 30.6 & $53.20(11.35)$ & \\
\hline Race & & & & 0.325 \\
\hline Malay & 165 & 91.7 & $52.04(11.67)$ & \\
\hline Non-Malay & 15 & 8.3 & $48.87(14.73)$ & \\
\hline Area of residency & & & & 0.613 \\
\hline Klang & 148 & 82.2 & $51.99(12.19)$ & \\
\hline Kuala Selangor & 32 & 17.8 & $50.81(10.81)$ & \\
\hline Employment status & & & & 0.064 \\
\hline Working & 113 & 62.8 & $50.51(13.36)$ & \\
\hline Housewife & 67 & 37.2 & $53.93(8.75)$ & \\
\hline Education level & & & & 0.570 \\
\hline$<12$ years & 62 & 34.4 & $52.48(10.75)$ & \\
\hline$>12$ years & 118 & 65.6 & $51.42(12.55)$ & \\
\hline Parity & & & & $0.020^{*}$ \\
\hline Uniparous & 75 & 41.7 & $48.60(12.76)$ & \\
\hline Multiparous & 105 & 58.3 & $54.05(10.82)$ & \\
\hline Level of income (Ringgit Malaysia, RM) & & & & 0.861 \\
\hline$<\mathrm{RM} 3000$ & 92 & 51.1 & $51.63(10.74)$ & \\
\hline$>$ RM3000 & 88 & 48.9 & $51.94(13.14)$ & \\
\hline Attitude to infant feeding & & & & $0.000^{*}$ \\
\hline Positive to formula feeding & 4 & 2.2 & $53.5(9.33)$ & \\
\hline Neutral & 146 & 81.1 & $49.97(11.87)$ & \\
\hline Positive to breastfeeding & 30 & 16.7 & $60.37(8.57)$ & \\
\hline
\end{tabular}

study done by Husin et al.(2017), they agreed on new and uniparous mothers who had no breastfeeding experience tend to have limited confidence in breastfeeding compared to multiparous mothers with multiple children. This is also coincided with literature that breastfeeding self-efficacy linked to exposure to past personal breastfeeding experience compared to first-time mothers (Bartle \& Harvey 2017). Personal experience of breastfeeding practices among mothers play an important role to explain attitude, subjective norms and self-efficacy of mothers to their next breastfeeding practices as intention to breastfeed were predicted by subjective norms and attitude of the mothers towards formulafeeding. It is also suggested that previous breastfeeding experience and prior exposure in breastfeeding predict one's intention and attitudes towards positive breastfeeding outcomes (Abdul Hamid \& Yahya 2018). 
Table 2. BSES-SF scores by mean, median and standard deviation $(n=180)$

\begin{tabular}{|c|c|c|c|}
\hline BSES-SF & Mean & Median & Standard deviation \\
\hline I can always determine that my baby is getting enough milk & 3.82 & 4.00 & 1.11 \\
\hline $\begin{array}{l}\text { I can always successfully cope with breastfeeding like I have with } \\
\text { other challenging tasks }\end{array}$ & 3.94 & 4.00 & 1.01 \\
\hline $\begin{array}{l}\text { I can always breastfeed my baby without using formula as a } \\
\text { supplement }\end{array}$ & 3.56 & 3.00 & 1.15 \\
\hline $\begin{array}{l}\text { I can always ensure that my baby is properly latched on for the } \\
\text { whole feeding }\end{array}$ & 3.99 & 4.00 & 0.99 \\
\hline I can always manage the breastfeeding situation to my satisfaction & 3.87 & 4.00 & 1.07 \\
\hline I can always manage to breastfeed even if my baby is crying & 3.58 & 4.00 & 1.10 \\
\hline I can always keep wanting to breastfeed & 3.88 & 4.00 & 0.98 \\
\hline $\begin{array}{l}\text { I can always comfortably breastfeed with my family members } \\
\text { present }\end{array}$ & 3.50 & 3.00 & 1.13 \\
\hline I can always be satisfied with my breastfeeding experience & 3.69 & 4.00 & 1.16 \\
\hline $\begin{array}{l}\text { I can always deal with the fact that breastfeeding can be time } \\
\text { consuming }\end{array}$ & 3.84 & 4.00 & 1.02 \\
\hline $\begin{array}{l}\text { I can always finish feeding my baby on one breast before switching } \\
\text { to the other breast }\end{array}$ & 3.38 & 3.00 & 1.13 \\
\hline I can always continue to breastfeed my baby for every feeding & 3.32 & 3.00 & 1.17 \\
\hline $\begin{array}{l}\text { I can always manage to keep up with my baby's breastfeeding } \\
\text { demands }\end{array}$ & 3.69 & 4.00 & 1.08 \\
\hline I can always tell when my baby is finished breastfeeding & 3.73 & 4.00 & 1.08 \\
\hline
\end{tabular}

BSES-SF: Breastfeeding Self Efficacy Scale-Short Form

Our study found that mothers' breastfeeding self-efficacy was correlated to their perceived attitude towards breastfeeding. In the Table 1, pregnant mothers who had higher score in IIFAS and had positive attitude towards breastfeeding $(60.37 \pm 8.57)$ had higher breastfeeding self-efficacy compared to those who were positive attitude towards formulafeeding (53.55 \pm 9.33$)$ and were neutral on infant feeding (49.97 \pm 11.87$)$. Higher score in IIFAS is associated with having good knowledge in breastfeeding (Dungy et al. 2008). Meanwhile, pregnant mothers who had more knowledge in breastfeeding displayed positive attitudes towards exclusive breastfeeding Utari et al. 2014) and is one of the predictor of breastfeeding intention (Abdul Hamid et al. 2017). Meanwhile, mothers with intention to exclusive breastfeed their newborns is linked to greater maternal confidence in breastfeeding and therefore, may foresee positive breastfeeding practices. Breastfeeding 
Table 3. Predictors of breastfeeding self-efficacy among expectant mothers $(\mathrm{n}=180)$

\begin{tabular}{|c|c|c|c|}
\hline & & $\begin{array}{l}\text { Regression } \\
\text { coefficients }\end{array}$ & $\begin{array}{c}\mathrm{p} \\
\text { value }\end{array}$ \\
\hline Intercept & 21.00 & & \\
\hline $\mathrm{R}^{2}$ value, BSES ${ }^{*}$ & 0.410 & & \\
\hline Parity & & 4.208 & $0.014^{*}$ \\
\hline Employment status & & 4.826 & $0.007^{*}$ \\
\hline Attitude & & 0.579 & $0.000^{*}$ \\
\hline \multicolumn{4}{|c|}{$\begin{array}{l}\text { Overal } \mathrm{R}^{2}=0.410 \text {; model fit: } \mathrm{F}=4.32 \\
\mathrm{p}<0.05 \text {; statistically significant (Stepwise method) } \\
\text { Parity: } 1=\text { =uniparous; } 2=\text { multiparous } \\
\text { Employment status: } 1=\text { employed; } 2=\text { housewife } \\
\text { Attitude: } 1=\text { ambivalent to infant feeding; } 2=\text { positive } \\
\text { towards breastfeeding } \\
{ }^{*} \text { Breastfeeding self efficacy scale }\end{array}$} \\
\hline
\end{tabular}

intention is defined as a mother's anticipated duration of breastfeeding, and this may predict the actual breastfeeding duration. Mothers with moderate to low level of breastfeeding self-efficacy tend to wean breastfeeding earlier two times higher than mothers with high selfefficacy. Mothers with high self-efficacy had intents to breastfeed for a lengthier period and this association is correlated well with parity whereby the exclusivity period was longer for the second child (Kronborg et al. 2018).

Employment status was also a predictor of breastfeeding self-efficacy. In Malaysia, percentage of labor force participation by female is $50.98 \%$ (The Global Economy 2018), meanwhile, the prevalence of breastfeeding among working mothers were high at $97.6 \%$ (Rashid et al. 2018). This study found that there is a correlation between breastfeeding support at workplace and breastfeeding self-efficacy. Working mothers tend to breastfeed their babies longer when their employer supporting breastfeeding practices by providing adequate facilities at work place such as breast pump and nursing room and also longer maternity leave (Alzaheb 2017).

To our knowledge, this present study is the first of its kind in Malaysia that discovered the predictors of breastfeeding self-efficacy among mothers during antenatal period. Breastfeeding self-efficacy is a modifiable factor, therefore early intervention should be carried out by targeting expectant mothers to improve breastfeeding rates (Brockway et al. 2017).

However, this present study has several limitations. This study was piloted in government health clinics. Majority of the participants came from average social class with high level of educational background. These findings may not be extrapolated to other settings with subjects who are less educated and from lower social class. On top of that, as of breastfeeding self-efficacy, it is self-reported and was taken only once from the mothers at various different trimesters. In addition, some predictors of breastfeeding selfefficacy was not taken into measurement such as past breastfeeding experience and social supports.

\section{CONCLUSION}

There are several autonomous variables that can influence maternal breastfeeding self-efficacy whether in form of modifiable factors or non-modifiable factors. This study suggested that determinants of breastfeeding self-efficacy among pregnant mothers in Malaysia are having positive attitude towards breastfeeding, being a housewife and had more than one child. Therefore, in order to increase breastfeeding rates, exposure to breastfeeding awareness and skill campaign should be given to expectant mothers especially mothers with their first child who have little experience in breastfeeding. In addition intervention to improve attitudes toward breastfeeding is also needed. Increasing supports from family and society as well as the employers by offering well-equipped breastfeeding facilities at workplace for working mothers are also crucial to increase the breastfeeding rate.

\section{ACKNOWLEDGEMENT}

This project was funded by Lestari Research Grant (600-IRMI/DANA5/3/ LESTARI(0101/2016) provided by Institute of Research Management and Innovation, MARA 
University of Technology, Selangor, Malaysia. Special thanks also to the pregnant mothers who had spent their time and shared their information with the researcher throughout this study. The authors have no conflict of interest.

\section{REFERENCES}

Abdul Hamid SB, Yahya N. 2018. Knowledge, attitude, prior exposure and intention to breastfeed among undergraduate university students. Journal Of Clinical And Health Sciences 3(2):26-35. doi:10.24191/jchs.v3i2.7083.

Abdul Hamid SB, Chih HJ, Binns CW. 2017. Predictors of breastfeeding intention in Malaysia. Environment Behavioral Proceeding Journal 2(5): 161-167. https://doi.org/10.21834/ebpj.v2i5.693.

Alzaheb RA. 2017. Factors Influencing Exclusive Breastfeeding in Tabuk, Saudi Arabia. Clin Med Insights Pediatr 11:1-8. https://doi. org/10.1177/1179556517698136.

Bandura A. 1977. Self-efficacy: Toward a unifying theory of behavioral change. Psychological Review 84(2): 191$215 . \quad$ https://doi.org/10.1037/0033295X.84.2.191.

Bartle NC, Harvey K. 2017. Explaining infant feeding: The role of previous personal and vicarious experience on attitudes, subjective norms, self-efficacy, and breastfeeding outcomes. $\mathrm{Br} \mathrm{J}$ Health Psychol 22(4):763-785. doi:10.1111/ bjhp.12254.

Binns C, Lee M, Low WY. 2016. The Long-term public health benefits of breastfeeding. Asia Pac J Public Health 28(1): 7-14. https://doi. org/10.1177/1010539515624964.

Brockway M, Benzies K, Hayden KA. 2017. Interventions to improve breastfeeding self-efficacy and resultant breastfeeding rates: A systematic review and meta-analysis. J Hum Lact 33(3):486-499. https://doi. org/10.1177/0890334417707957.

Castro RTA, Glover V, Ehlert U, Connor TG. 2017. Antenatal psychological and socioeconomic predictors of breastfeeding in a large community sample. Early Human Development 110:50-56. https://doi.org/10.1016/j. earlhumdev.2017.04.010.

Dennis CL. 1999. Theoretical underpinnings of breastfeeding confidence: A self-efficacy framework. J Hum Lact 15(3):195-201. https://doi. org/10.1177/089033449901500303.

Dennis CL. 2003. The breastfeeding selfefficacy scale: Psychometric assessment of the short form. J Obstet Gynecol Neonatal Nurs 32(6):734-744. https:// doi.org/10.1177/0884217503258459.

Draman N, Mohammad N, Yusoff HM, Muhamad R. 2017. The decision of breastfeeding practices among parents attending primary health care facilities in suburban Malaysia. Journal of Taibah University Medical Sciences 12(5):412417 . https://doi.org/10.1016/j. jtumed.2017.05.005.

Dungy CI, McInnes RJ, Tappin DM, Wallis AB, Oprescu F. 2008. Infant feeding attitudes and knowledge among socioeconomically disadvantaged women in Glasgow. Matern and Child Health J 12:313-322. https://doi. org/10.1007/s 10995-007-0253-9.

Eidelman AI, Schanler RJ, Johnston M. 2012. Breastfeeding and the use of human milk. Pediatrics 129(3):e827-e841. https://doi.org/10.1542/peds.2011-3552.

Husin H, Isa ZM, Latif KA, Ariffin R, Rahman SA, Ghazi HF. 2017. The Malay version of antenatal and postnatal breastfeeding self-efficacy scale-short form: Reliability and validity assessment. Malaysian Journal of Public Health Medicine. 17(2):62-69.

Institute for Public Health. 2016. National Health and Morbidity Survey 2016: Maternal and Child Health Volume II. Kuala Lumpur: Institute for Public Health, National Institutes of Health, Ministry of Health Malaysia.

Karande S, Parkar S. 2012. Do fathers' attitudes support breastfeeding? A cross-sectional questionnaire-based study in Mumbai, India. Indian JMed Res 66(1):30-39. doi:10.4103/0019-5359.110861.

Koskinen KS, Aho AL, HAnnula L, Kaunonen M. 2014. Maternity hospital practices 
and breast feeding self-efficacy in Finnish primiparous and multiparous women during the immediate postpartum period. Midwifery 30:464-470. https:// doi.org/10.1016/j.midw.2013.05.003.

Krejcie R V, Morgan DW. 1970. Determining sample size for research activities. Educ Psychol Meas 607-610. https://doi. org/10.1177/001316447003000308.

Kronborg H, Foverskov E, Vaeth M, Maimburg RD. 2018. The role of intention and self-efficacy on the association between breastfeeding of first and second child, a Danish cohort study. BMC Pregnancy Childbirth 18:454. https:// doi.org/10.118.

Leahy-Warren P, Mulcahy H, Phelan A, Corcoran P. 2014. Factors influencing initiation and duration of breast feeding in Ireland. Midwifery 30(3): 345-52. https://doi.org/10.1016/j. midw.2013.01.008.

Mannion CA, Hobbs AJ, McDonald SW, Tough SC. 2013. Maternal perceptions of partner support during breastfeeding. Int Breastfeed J (8):4. http://dx.doi. org/10.1186/1746-4358-8-4.

Meedya S, Fahy K, Kable A. 2010. Factors that positively influence breastfeeding duration to 6 months: A literature review. Women and Birth 23(4): 135-145. https:// doi.org/10.1016/j.wombi.2010.02.002.

Mirghafourvand M, Malakouti J, MohammadAlizadeh-Charandabi S, Faridvand F. 2018. Predictors of breastfeeding selfefficacy in Iranian women: A crosssectional study. International Journal of Women's Health and Reproduction Sciences 6(3):380-385. 10.15296/ ijwhr.2018.62.

Mora ADL, Russell DW, Dungy CI, Losch M, Dusdieker L. 1999. The Iowa infant feeding attitude scale: Analysis of reliability and validity. J Appl Soc Psychol 29(11):2362-2380. https:// doi.org/10.1111/j.1559-1816.1999. tb00115.x.

Noel-Weiss J, Rupp A, Crag B, Bassett V, Woodend AK. 2006. Randomized controlled trial to determine effects of prenatal breastfeeding workshop on maternal breastfeeding self-efficacy and breastfeeding duration. $\mathrm{J}$ Obstet Gynecol Neonatal Nurs 35(5):616624. https://doi.org/10.1111/j.15526909.2006.00077.x.

Rashid AA, Shamsuddin NH, Ridhuan RDARM, Sallahuddin NA, Devaraj NK. 2018. Breastfeeding practice, support, and self-efficacy among working mothers in a rural health clinic in Selangor. Mal J Med Health Sci 14(2): 39-49.

Shukri NHM, Wells J, Mukhtar F, Lee MHS, Fewtrell M. 2017. Study protocol: An investigation of mother-infant signalling during breastfeeding using a randomised trial to test the effectiveness of breastfeeding relaxation therapy on maternal psychological state, breast milk production and infant behaviour and growth. Int Breastfeed J 12(33):114. https://doi.org/10.1186/s13006-0170124-y.

The Global Economy. 2018. Malaysia: female labor force participation. [Internet]. https://www.theglobaleconomy. com/Malaysia/Female_labor_force_ participation/ [Accessed 29th June 2019].

Tokat MA, Okumus H, Dennis CL. 2010. Translation and psychometric assessment of the breast-feeding self efficacy scale-short form among pregnant and posnatal women in Turkey. Midwifery 26(1):101-108. https://doi. org/10.1016/j.midw.2008.04.002.

Utarir AP, Rosita K, Damanik MRM. 2014. Pengetahuan gizi, keluhan kesehatan, kondisi psikologi, dan pola pemberian asi ibu postpartum. Jurnal Gizi dan Pangan 8(3):187-192. https://doi.org/10.25182/ jgp.2013.8.3.187-194.

Victora CG, Bahl R, Barros AJD, Franca GVA, Horton S, Kresevec J, Murch S, Sankar MJ, Walker N, Rollins NC. 2016. Breastfeeding in the 21 st century: Epidemiology, mechanisms, and lifelong effect. The Lancet 387(10017):475490. https://doi.org/10.1016/S01406736(15)01024-7.

[WHO] World Health Organization. Global targets 2025: To improve maternal, infant and young child nutrition. 2019. http://www.who. 
Abdul Hamid \& Zaidi

int/nutrition/global-target-2025/ en/ [Accessed 25th June 2019].

Yang X, Gao LL, Ip WY, Chan WCS. 2016. Predictors of breast feeding self-efficacy in the immediate postpartum period: A cross-sectional study. Midwifery
41:1-8. https://doi.org/10.1016/j. midw.2016.07.011.

Zhu Y, Zhang Z, Ling Y, Wan H. Impact of intervention on breastfeeding outcomes and determinants based on theory of planned behavior. Women and Birth 30(2): 146-152 https://doi.org/10.1016/j. 